\title{
Erratum to: Stress fracture of the ulna associated with bisphosphonate therapy and use of walking aid
}

\author{
G. S. H. Chiang • K. W. B. Koh • T. W. Chong • B. Y. Tan
}

Published online: 5 June 2014

(C) International Osteoporosis Foundation and National Osteoporosis Foundation 2014

Erratum to: Osteoporos Int

DOI 10.1007/s00198-014-2739-9

The authors' names were rendered incorrectly; the corrected names are given here.

The publisher apologizes for the inconvenience caused.

The online version of the original article can be found at http://dx.doi.org/ $10.1007 / \mathrm{s} 00198-014-2739-9$.

G. S. H. Chiang $(\bowtie)$

National University Health System, 1E, Kent Ridge Road,

Singapore 119228, Singapore

e-mail: grace_sh_chiang@nuhs.edu.sg

K. W. B. Koh • T. W. Chong • B. Y. Tan

St. Luke's Hospital, 2 Bukit Batok Street 11, Singapore 659674,

Singapore 